\title{
Lieber Henry E. Sigerist
}

Der GESNerus möchte Ihnen im Namen der Schweizerischen Gesellschaft für Geschichte der Medizin und der Naturwissenschaften Glïckwunsch und Dank sagen für Anregung, Förderung und Ermutigung, die von Ihrem rastlosen und überaus fruchtbaren Wirken an hervorragender Stelle stets ausgegangen sind. Die vor neun Jahren mit JeAN Strohl gemeinsam geplante kleine Zeitschrift GESNERUS, deren Geburt der leider zu früh am 7. Oktober 1942 verstorbene unvergeßliche Biologiehistoriker und Zoologe SтrонL nicht mehr erlebt hat, wäre wohl ohne eine solche Ermunterung nicht zustandegekommen, vielleicht nicht einmal gewagt worden. Nicht daß Sie dem GESNERUS bei seinem Ins-Licht-Treten Pate gestanden hätten - aber man durfte sich irgendwie darauf beziehen, daß in Amerika an der Johns Hopkins.University in Baltimore ein Schweizer schaffhauserischer Abkunft am Werke sei, der die wissenschaftlichen Grundlagen der Geschichte der Medizin neu gelegt und ihren Wirkungsbereich und ihre Bedeutung im Gesamtrahmen der historischen Wissenschaften neu bestimmt hatte. Vorbildlich und programmatisch war in dieser Hinsicht Ihr Aufsatz über Wert und Bedeutung der Medizingeschichte aus Ihrer Leipziger Zeit, ein Thema, das Sie auf breiter Grundlage und zu einer Gesamtpädagogik der Medizin erweiternd in verschiedenen Ihrer Bücher, zuletzt in The University at the Crossroads (1946) weiter ausgeführt und zu einem vielbeachteten Werk über Hochschulpädagogik ausgeweitet haben.

Solcher Ermutigungen bedurfte es um so mehr, als der in Kriegszeiten gegründete GESNERUS seinen Lauf mit einem Heft der Nekrologe beginnen mußte: Neben Jean Strohl war dieses erste Heft dem Wirken Arnold C. KLEBS gewidmet, gestorben am 6. März 1943, einem «unsichtbaren» Förderer der kleinen Zeitschrift, den sie verlor, ehe sie das Licht der Welt erblickte, und der bald leise mahnend, bald vernehmlich pochend, auf die Notwendigkeit der Gründung einer schweizerischen medizinhistorischen Zeitschrift hinwies.

Unsere Gesellschaft hat weiteren Anlaß, Ihrer in diesem Jahre dankbar zu gedenken: sind es doch gerade dreißig Jahre her, seit Sie am 4. Dezember 1921 in Bern mit André Guisan, R. von Fellenberg, Arnold C. Klebs, W. von Rodt, Gustav Senn und J. Strohl zusammen, das Amt des Sekretärs tatkräftig übernehmend, die Schweizerische Gesellschaft für Geschichte der Medizin und der Naturwissenschaften gründeten.

Seither sind viele Jahre ins Land gegangen, und mit wechselndem Glück, aber sich stets behauptend, hat die Gesellschaft die Fährnisse der Zeiten über- 
standen und ihre Existenzberechtigung immer wieder neu bewiesen. Sie sind inzwischen dem Stern Ihres Wirkens erst nach Deutschland, dann nach Amerika gefolgt und haben der Medizingeschichte in Forschung und Unterricht neue Wege gewiesen.

Bei einem humanistisch so durchgebildeten Europäer, wie Sie es sind, ist es ebenso erstaunlich wie bedeutsam, daß Sie nicht den Bildungswert der Medizingeschichte in den Vordergrund gestellt haben, sondern stets darauf ausgegangen sind, die Grundlegung der Medizin in ihrem ideellen Werden und in den $\mathrm{Zu}$ sammenhängen der historisch bedingten Geistesströmungen zu sehen und gleichzeitig die soziale Funktion der Medizin historisch, aktuell und zukünftig, d.h. in ihrer prospektiven Potenz, zu erkennen. Sie teilen in gewissem Sinn den Fortschrittsoptimismus großer sozialer Vorkämpfer und sehen in einzigartiger Weise Ihre Aufgabe als Medizinhistoriker, Ihr Ziel und den Sinn Ihres Werkes im großen Rahmen einer «Weltmedizin», deren Vollendung im Zusammenwirken historischer, soziologischer, kultureller und wirtschaftlicher Gegebenheiten, Strömungen, Ideen gesucht und ständig erneuert werden muß. Dadurch sind Sie nicht nur ein großer Erneuerer der Medizingeschichte, sondern auch ein Neuerer, indem Sie bewußt die Medizingeschichte in den Rahmen der heutigen Medizin, der Kultur und des sozialen und wirtschaftlichen Lebens hineingestellt und ihr damit einen viel universelleren (in gewissem Sinn vielleicht auch bescheideneren) Rahmen, aber gleichzeitig eine lebendige Funktion gegeben haben, welche heute ganz besonders auf dem Gebiete der Naturwissenschaftsgeschichte ihre reichen Früchte trägt.

Ihr Lebenswerk und der Wunsch, es zu vollenden, haben Sie wieder in Ihre Heimat zurückgeführt. Der erste Band Ihrer monumentalen History of Medicine hat in diesem Jahr das Licht der Welt erblickt. Mögen die kommenden Jahre der angestrengt-stillen Tätigkeit, welche Sie in der schönen Abgeschiedenheit Ihrer Pura-Klause dem Werden Ihres Werkes widmen, Ihnen auch jene glückverheißende «serenità» stets erhalten, welche der Name des Hauses dem Kommenden kündet.

Nehmen Sie, verehrter Jubilar, diesen kleinen Festband des GESNERus als Zeichen des Dankes all derjenigen entgegen, welche durch Sie in Gespräch und Schrift Anregung, Förderung und Hilfe empfingen und die ihren Dank durch einen Beitrag zu dieser Festschrift bekunden wollten.

H. Fischer 